\title{
UNIDADES DE CONSERVAÇÃO DA NATUREZA: DIAGNÓSTICO DO PROGRAMA ESTADUAL DE UNIDADES DE CONSERVAÇÃO-PEUC NO RIO GRANDE DO NORTE- BRASIL
}

\section{STORAGE UNITS OF NATURE: DIAGNOSTIC PROGRAM STATE STORAGE UNITS-PSSU IN THE STATE OF RIO GRANDE DO NORTE-BRAZIL}

\author{
Estevão A. L. Santos ${ }^{1}$; Carlos E. de M. Jerônimo² \\ ${ }^{1}$ Arquiteto e Urbanista, Servidor público do Instituto de Desenvolvimento Sustentável e Meio Ambiente- IDEMA. \\ Especialização em Gestão e Perícia Ambiental - UNI-RN (Natal). E-mail: estevaolucio@uol.com.br \\ ${ }^{2}$ Professor Orientador - UNI-RN. E-mail: c enrique@hotmail.com
}

http://dx.doi.org/10.5902/223613087680

\section{RESUMO}

A implantação de Unidades de Conservação da Natureza no Rio Grande do Norte/Brasil, sob responsabilidade estadual, é competência do Instituto de Desenvolvimento Sustentável e Meio Ambiente- IDEMA. Esta pesquisa desenvolve um estudo preliminar para avaliação da gestão nessas áreas protegidas. O método utilizado foi o RAPPAM, (Avaliação Rápida e Priorização da Gestão de Unidades de Conservação) desenvolvido pela.WWF e utilizado em diversos estados do Brasil.. A coleta de dados apresentou dois vieses: um direto sob forma de questionários aplicados aos gestores e funcionários de 2 unidades de conservação. 0 indireto foi a análise documental das legislações com as definições e normas aplicadas as diferentes UCs. O objetivo foi relacionar a implantação do Programa Estadual de Unidades de Conservação - PEUC e as recomendações do Sistema Nacional de Unidades de Conservação-SNUC e outros documentos sobre UCs definindo um diagnóstico preliminar do estágio atual das Unidades de Conservação criadas pelo governo estadual. Como resultado relaciona-se as UCs instituídas com os objetivos para os quais foram criadas e as melhorias que apresentaram a região onde elas estão inseridas. Essa avaliação feita por análise das diretrizes teóricas e da gestão de UCs observou o estágio atual das UCs estaduais. Nela abordaram-se aspectos político-institucionais, administrativos e fundiários e as relações com a população local. Como respostas preliminares observam-se que a gestão desses territórios legalmente protegidos, está sendo implementada de forma satisfatória. Já a pressão antrópica e a falta de prioridade à conservação da biodiversidade dos recursos naturais, tanto pelo governo como pela população, inviabiliza uma gestão alinhando conservacionismo e sustentabilidade. Um número bastante preocupante já se inicia pelo número de UC estaduais criadas.

Palavras-chave: Unidades de Conservação/RN, Gestão Ambiental potiguar, SNUC, Programa Estadual de Unidades de Conservação/RN-PEUC/RN; RAPPAM Gestão no RN

\footnotetext{
ABSTRACT

The deployment of Conservation of Nature in Rio Grande do Norte / Brazil, under state responsibility, competence is the Institute of Sustainable Development and Environment-IDEMA. This research develops a preliminary study to evaluate management in these protected areas. The method used was RAPPAM (Rapid Assessment and Prioritization of Protected Areas Management) 
pela.WWF developed and used in several states in Brazil. Data collection presented two biases: a direct form of questionnaires to managers and employees of two conservation units. The analysis was indirect documentary of laws with definitions and standards applied in different UCs. The aim was to relate the implementation of the State Program of Conservation - PEUC and recommendations of the National System of Conservation Units-SNUC and other documents on PAs defining a preliminary diagnosis of the current status of Conservation Units established by the state government. As a result relates to the UCs established with the objectives for which they were created and the improvements that showed the region where they are located. This assessment by analyzing the theoretical guidelines and management of PAs, noted the current status of state UCs. It is addressed aspects politico-institutional, administrative and land and relations with the local population. As preliminary answers can be observed that the management of these territories legally protected, is being implemented satisfactorily. Already anthropic pressure and lack of priority for biodiversity conservation of natural resources, both the government and the population, prevents management aligning conservationism and sustainability. A number already quite worrying starts by the number of UC state created.

Keywords: Protected Areas, Environmental Management, SNUC, the State Program of Conservation-PSSU.

\section{INTRODUÇÃo}

Há algum tempo que os observadores e estudiosos externam a sua preocupação com a qualidade de vida do planeta. Desde o século XIX já se observava que o homem atentava para as questões de cunho ambiental, mas a intensificação e o reconhecimento da comunidade internacional quanto a elas ocorrem, de fato, no século XX (QUEIROZ, 2003).

A problemática ambiental passou a ser uma preocupação mundial ao final da década de 1960, e trouxe conceitos como o do Desenvolvimento Sustentável ou da proteção dos Espaços Naturais, como forma de assegurar a sobrevivência digna dos seres vivos. Atualmente, a criação de Unidades de Conservação (UCs) é uma das principais medidas legais, adotadas pela maioria das nações do mundo, para a proteção e a conservação dos recursos naturais, Acreditava-se que as UCs funcionaram como territórios de conservação capazes de diminuir os impactos advindos da transformação das paisagens naturais pelas atividades humanas. Sua importância surgiu da necessidade de se manter estoques de recursos naturais para as gerações presentes e futuras e paisagens especiais que, possivelmente, não poderiam ser vistas no futuro próximo caso os crescentes níveis de degradação ambiental se mantivessem. A conservação da natureza segundo o modelo de Unidades de Conservação, ou áreas protegidas, é resultado direto dessas preocupações ambientais e sua concepção remonta à segunda metade do século XIX (MILLER, 1997).

No Brasil, a instituição do Sistema Nacional de Unidades de Conservação-SNUC, Lei no 9.985 (BRASIL, 2000) e a sua posterior regularização incrementaram a criação de UCs, em todo o país, uma vez que incentiva e norteia a criação das referidas unidades.

No Estado do Rio Grande do Norte, apesar do esforço técnico para a criação e gestão de novas UCs, observa-se, no dia a dia da instituição gestora, o Instituto de Desenvolvimento Sustentável e Meio Ambiente- IDEMA, alguns entraves que afetam a boa implementação das UCs estaduais.

Esse Artigo tem como objetivo analisar, à luz da legislação que regulamentas as Unidades de Conservação no país e do estado, a implantação do Programa Estadual de Unidades de 
Conservação-PEUC no Rio Grande do Norte, enquadrando o estágio atual em que se encontram as UCs, a fim de verificar em que sentido estas áreas vêm cumprindo com seus objetivos de conservação do patrimônio natural. Para consecução do objetivo foram coletadas informações constantes na legislação pertinente, nos documentos relativos às UCs, publicados pelo Ministério do Meio Ambiente e outros produzidos pelo próprio IDEMA, além da importante contribuição dos técnicos lotados no Núcleo de Unidades de Conservação - NUC/IDEMA. Essa etapa visou identificar as políticas estabelecidas no trato da questão.

O método utilizado para avaliar a gestão dessas áreas protegidas foi uma adaptação do Rappam (ERVIN, 2003), sigla em inglês para Avaliação Rápida e Priorização da Gestão de Unidades de Conservação. O Rappam é uma das metodologias mais utilizadas em todo o mundo para avaliar rapidamente a efetividade de gestão das áreas protegidas. A pesquisa foi realizada por meio de questionários aplicados aos gestores e funcionários das unidades de conservação. As respostas foram analisadas e os resultados sistematizados com relação ao contexto, planejamento, insumos, processos e resultados que as UCs vêm atingindo nos últimos anos. Espera-se com isso obter um diagnóstico preciso das Unidades de Conservação, que contribua com informações que possam contribuir para o debate e a consolidação do Programa Estadual de Unidades de Conservação e auxiliar os órgãos responsáveis pela gestão do Sistema, no Estado do Rio Grande do Norte.

$O$ estudo avaliou se as unidades de conservação estaduais, sob responsabilidade do governo do estado do Rio Grande do Norte, estão cumprindo o seu objetivo de conservação da natureza, se tem um planejamento efetivo, se estão vulneráveis ou sofrendo ameaças, e ainda se possuem recursos suficientes para a sua gestão.

\section{AS UNIDADES DE CONSERVAÇÃO DA NATUREZA E A LEI DO SNUC}

O Brasil exerce, no contexto da preservação da natureza, um importante papel no cenário mundial uma vez que abriga a maior diversidade biológica do planeta e uma boa parte dos recursos naturais existentes.

Uma das melhores alternativas conhecidas para a preservação desta biodiversidade são os Sistemas de Unidades de Conservação que, embora por si só não representem uma solução definitiva, constituem-se peças fundamentais na luta pela preservação do patrimônio ambiental do país (BRASIL, 2002).

No âmbito nacional, após sete anos de tramitação e debates, foi aprovado, no dia 10 de junho de 1999, o Projeto de Lei n.o 2892/92 (BRASIL, 1992) que dispõe sobre o Sistema Nacional de Unidades de Conservação da Natureza e que finalmente resultou na aprovação da lei n. 99985 de 18 de julho de 2000 (BRASIL, 2000) que, dentre outras providências, institui o SNUC, estabelece critérios e normas para a criação, implementação e gestão das Unidades de Conservação, bem como regulamenta o artigo 225, § 1으, incisos I, II, III e VII da Constituição Federal de 1988 (BRASIL, 1988).

O Sistema Nacional de Unidades de Conservação da Natureza, ou simplesmente SNUC, é constituído pelo conjunto das unidades de conservação federais, estaduais e municipais, sendo a definição de Unidade de Conservação, de acordo com esta lei:

O espaço territorial e seus recursos ambientais, incluindo as águas jurisdicionais, com características naturais relevantes, legalmente instituído pelo poder público, com objetivos de conservação e limites definidos, sob regime especial de administração, ao qual se aplicam garantias adequadas de proteção (BRASIL, 2000, art. 2으, inciso I). 
As unidades de conservação integrantes do SNUC dividem-se em dois grupos com características específicas: as Unidades de Proteção Integral e as Unidades de Uso Sustentável.

As Unidades de Proteção Integral tem por objetivo preservar a natureza, sendo admitido apenas o uso indireto dos seus recursos naturais respeitadas as exceções previstas na lei. Já as Unidades de Uso Sustentável buscam compatibilizar a conservação da natureza com o uso sustentável de parte dos seus recursos naturais (art. 7으, § 1으 e 2ㅇda lei do SNUC).

As categorias de unidade de conservação integrantes destes dois grupos, com base em suas características específicas, são assim definidas:

Tabela 1 - Categorias de Unidades de Conservação

\begin{tabular}{|c|c|}
\hline UNIDADES DE PROTEÇÃO INTEGRAL & UNIDADES DE USO SUSTENTÁVEL \\
\hline Estação Ecológica & Área de Proteção Ambiental \\
\hline Reserva Biológica & Área de Relevante Interesse Ecológico \\
\hline Parque Nacional & Floresta Nacional \\
\hline Monumento Natural & Reserva Extrativista \\
\hline Refúgio da Vida Silvestre & Reserva de Fauna \\
\hline & Reserva de Desenvolvimento Sustentável \\
\hline & Reserva Particular do Patrimônio Natural \\
\hline
\end{tabular}

Fonte: Lei n. 9985 (SNUC, 2000).

Ao analisarmos o texto do SNUC, as Unidades de Conservação são criadas com os seguintes objetivos: I - contribuir para a manutenção da diversidade biológica e dos recursos genéticos no território nacional e nas águas jurisdicionais; II - proteger as espécies ameaçadas de extinção no âmbito regional e nacional; III - contribuir para a preservação e a restauração da diversidade de ecossistemas naturais; IV - promover o desenvolvimento sustentável a partir dos recursos naturais; $V$ - promover a utilização dos princípios e práticas de conservação da natureza no processo de desenvolvimento; $\mathrm{VI}$ - proteger paisagens naturais e pouco alteradas de notável beleza cênica; VII - proteger as características relevantes de natureza geológica, geomorfológica, espeleológica, arqueológica, paleontológica e cultural; VIII - proteger e recuperar recursos hídricos e edáficos; IX - recuperar ou restaurar ecossistemas degradados; X - proporcionar meios e incentivos para atividades de pesquisa científica, estudos e monitoramento ambiental; XI valorizar econômica e socialmente a diversidade biológica; XII - favorecer condições e promover a educação e interpretação ambiental, a recreação em contato com a natureza e o turismo ecológico; XIII - proteger os recursos naturais necessários à subsistência de populações tradicionais, respeitando e valorizando seu conhecimento e sua cultura e promovendo-as social e economicamente.

De acordo com o texto da lei do SNUC, o Plano de Manejo definido e aprovado por um Conselho Consultivo, com representante dos principais agentes que atuam na área, é o documento que define e determina as prioridades e as atividades a serem desenvolvidas numa Unidade de Conservação. Esse plano deve ser estabelecido num prazo de até 5 anos após a criação legal da área como Unidade de Conservação. Esse plano deve conter todas as ações e toda estrutura gestora das ações a serem desenvolvidas na Unidade. 


\section{MATERIAIS E MÉTODOS}

O estudo relaciona a situação atual da gestão das unidades de conservação criadas e geridas pelo estado do Rio Grande do Norte. Constitui-se de uma pesquisa aplicada, pois desenvolve um estudo preliminar para avaliação da gestão nessas áreas protegidas.. A coleta de dados apresentou dois vieses: um direto sob forma de questionários aplicados aos gestores e funcionários de 2 unidades de conservação. $O$ indireto foi a análise documental das legislações com as definições e normas aplicadas as diferentes UCs. O objetivo foi relacionar a implantação do Programa Estadual de Unidades de Conservação - PEUC e as recomendações do Sistema Nacional de Unidades de Conservação-SNUC e outros documentos sobre UCs definindo um diagnóstico preliminar do estágio atual da gestão das Unidades de Conservação criadas pelo governo estadual.

Do ponto de vista dos objetivos, trata-se de um estudo exploratório-descritivo, o qual descreve os resultados buscando caracterizar a gestão das unidades de conservação estaduais de maneira quantitativa e qualitativa..

Do ponto de vista dos procedimentos técnicos, o estudo caracteriza-se como pesquisa bibliográfica relacionando dados técnicos, normas e resultados obtidos pelos questionários e por estudos técnicos, sob forma de relatórios gerados pelo próprio IDEMA..

A estrutura da pesquisa consistiu em:

- Formulação do problema, englobando a justificativa do estudo, a determinação dos objetivos, a contextualização da problemática e definição da metodologia;

- Realização do levantamento teórico, que orienta a caracterização do objeto de estudo, as definições e conceitos a serem utilizados em análise e correntes de pensamentos que norteiam a hipótese da pesquisa;

- Levantamento de dados em campo, por meio de incursões investigativas em unidades de conservação estaduias do Rio Grande do Norte;

- Apresentação de resultados avaliativos do processo de gestão das unidades estaduais das unidades de conservação e discussão ações que proporcione melhorias na gestão das unidades de conservação estaduais do RN.

Os dados coletados foram organizados e utilizados para elaboração do levantamento das principais resultados e a discussão oportunas focando ações que otimizem a gestão das unidades de conservação estaduais do RN.

\section{RESULTADOS E DISCUSSÕES}

As Unidades de Conservação no Rio Grande do Norte apresentam sua história ligada inicialmente a "trocas" por obras governamentais a ser construída: este é o caso do Parque das Dunas criado em 1978, como contraponto a construção da Via Costeira e seus locais para obras de hotéis visando o turismo próximo a orla, O outro caso é a do Parque Estadual Florêncio Luciano, criado em 1988, que é a área do açude do Boqueirão e adjacências, em Parelhas cujo espelho d’água é uma unidade de conservação. Outro caso é a Apa Bonfim-Guairá criada sob pressão devido a adutora Monsenhor Expedito cujo reservatório é a Lagoa do Bonfim e suas lagoas comunicantes principalmente no município de Nísia Floresta. A excessão inicial foi a primeira Reserva Criada em 1950: A Floresta Nacional de Açu -FLONA de Açu que auxilia nas pesquisas e cultivo de mudas nativas e exóticas implantada pelo Governo Federal, pelo antigo IBDF, hoje 
IBAMA e administrada atualmente pelo Instituto Chico Mendes. Outra exceção inicial focado na proteção ambiental está Reserva Biológica do Atol das Rocas com proteção integral cujas espécies são protegidas (IDEMA, 2011).

Atualmente foi mudado o foco tendo as unidades de conservações sendo propostas por preservar ambientes com formações vegetais, geológicas, hídricas e de reprodução animal além de fixar populações tradicionais na procura do desenvolvimento sustentável. Hoje existem 17 Unidades de Conservação (UCS) legalmente constituídas no território potiguar (vê mapa, sendo nove estaduais, cinco federais, três particulares e uma municipal (IDEMA,2012).

\section{UNIDADES DE CONSERVAÇÃO NO RIO GRANDE DO NORTE}

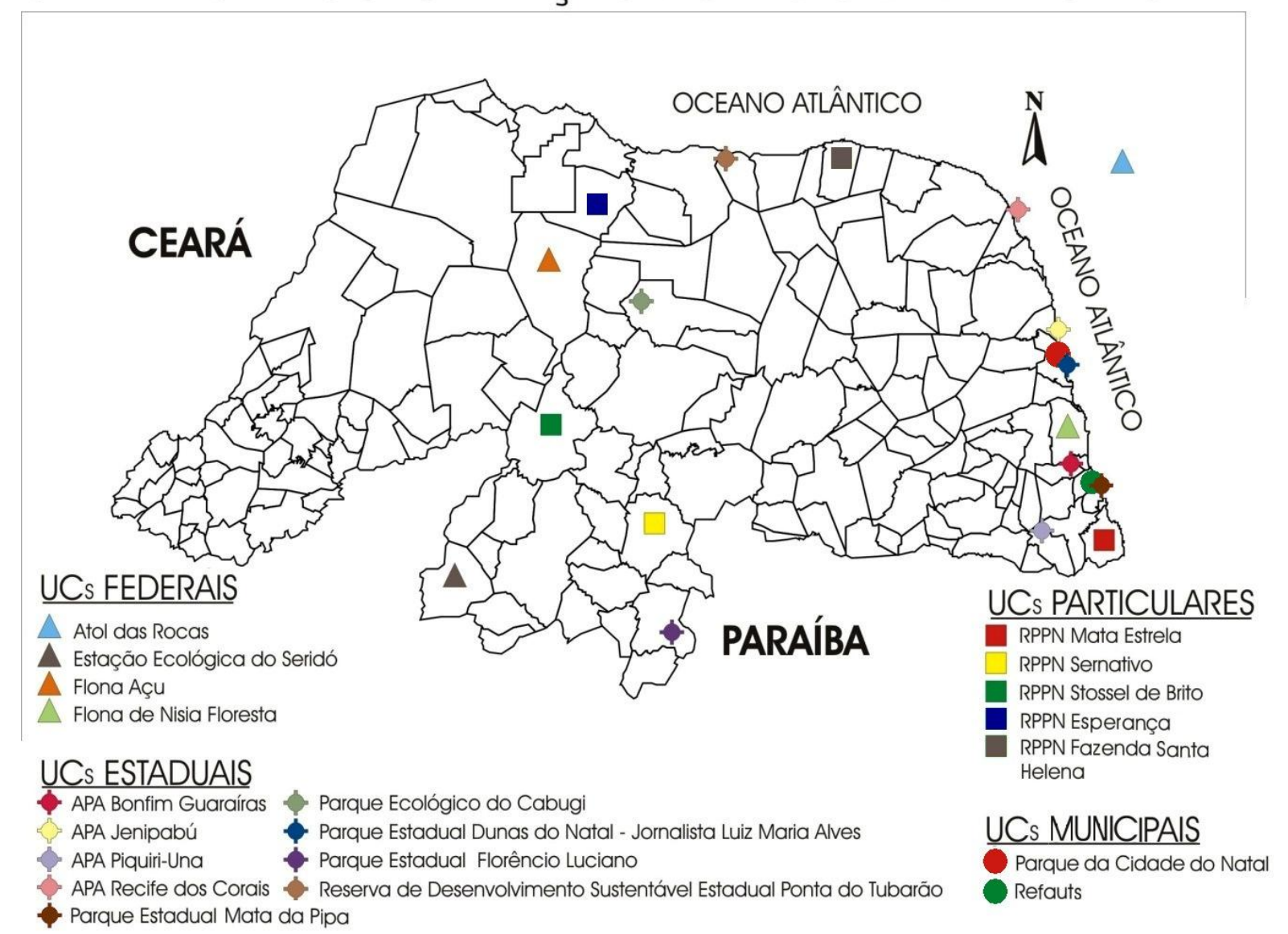

Figura 1. Unidades de Conservação do RN.

De acordo com o documento IDEMA (2011), as UCs totalizam 294.139 ha, sendo 41.039 ha (14\%) em Unidades de Proteção Integral e 253.100 ha (86\%) em Unidades de Uso Sustentável. Somente as quatro Áreas de Proteção Ambiental (APAs) respondem por 236.827 ha (81\%) desse total. A União responde por 37.802 ha (13\%) das áreas protegidas, enquanto o poder público estadual responde por 253.400 ha (86\%) e a iniciativa privada, por 2.937 ha (1\%). A grande maioria das áreas em UCs (220.156 ha) envolve zonas oceânicas costeiras rasas, atois e recifes, ou seja, $75 \%$ das áreas protegidas do Rio Grande do Norte.

Segundo o estudo, considerando que a área territorial oficial do Rio Grande do Norte totaliza 52.796,791 km2 (IBGE, 2002), constata-se, a partir dos dados apresentados, que apenas $1,4 \%$ das terras emersas do Estado encontram-se dentro de UCs. Tal situação torna-se 
preocupante na medida em que esses quantitativos estão abaixo da média nacional de UCs, que está em torno de $6 \%$, e bem abaixo das recomendações técnicas, que indicam cerca de $10 \%$ dos territórios nacionais destinados à preservação.

O governo do Rio Grande do Norte criou, em 2004, no IDEMA- Instituto de Defesa do Meio Ambiente, o Núcleo de Unidades de Conservação-NUC, e instituiu o PROGRAMA DE CONSERVAÇÃO E RECUPERAÇÃO AMBIENTAL, constante do PLANO DE AÇÃO PLURIANUAL do Governo do Estado, que estabelece, como meta, ampliar até 2011, as áreas legalmente protegidas para cerca de $6 \%$ do território potiguar. Isto exigirá a destinação de cerca de 243.000 ha de terras à proteção ambiental, mais do que triplicando as áreas continentais destinadas à conservação no Rio Grande do Norte.

Para atingir a meta estabelecida no PROGRAMA DE CONSERVAÇÃO E RECUPERAÇÃO AMBIENTAL, estão aprovadas pelo CONEMA e em fase de criação pelo governo estadual, até junho de 2008, três novas UCs: Área de Proteção Ambiental Dunas do Rosado, Parque Estadual dos Mangues e Parque Estadual do Jiqui. Juntas, adicionarão 17.774 ha às áreas protegidas, elevando para 18 o número de UCs no Estado. Outras três UCs estão com os seus estudos em fase de conclusão e serão criadas até o final do presente ano, a saber: Monumento Natural Morro do Careca, APA das Carnaúbas e uma UC das Cavernas, num total aproximado de 77.550 ha. Quando implantas, a área protegida em UCs se elevará a 3,2\% do território potiguar.

Como forma de subsidiar a instituição das novas Unidades de Conservação, como o objetivo de elevar o percentual de área protegidas para mais de $6 \%$ de sua área territorial, até o ano de 2011, o IDEMA efetuou um levantamento intitulado "ESTUDOS TÉCNICOS E CARACTERIZAÇÃO PRELIMINAR DAS ÁREAS POTENCIAIS PARA CRIAÇÃO DE NOVAS UNIDADES DE CONSERVAÇÃO NO ESTADO DO RIO GRANDE DO NORTE", que apresenta algumas diretrizes a serem consideradas num programa de expansão das UCs no Rio Grande do Norte, destacando-se:

- estimulo à criação de UCs municipais, sobretudos monumentos naturais e parques envolvendo serras, inselbergs e fragmentos florestais;

- estimulo à criação de RPPNs;

- prioridade à criação de UCs de proteção integral;

- prioridade à criação de UCs na Caatinga;

- criação de UCs envolvendo estuários, matas ciliares e praias;

- produção de um protocolo para caracterização das áreas passíveis de se tornar UC;

- envolvimento de especialistas de diversas áreas para a execução do protocolo referido;

A previsão é que, até 2011, um total de vinte e duas(22) UCs estaduais estejam criadas e implementadas, com os seus conselhos gestores empossados e com os seus respectivos Planos de Manejo iniciados.

Tabela 2 - Áreas prioritárias para a criação de unidades de conservação,

Onde: $\mathrm{PI}=$ Proteção Integral e US = Uso Sustentável.

\begin{tabular}{|c|l|l|c|}
\hline Ordem & \multicolumn{1}{|c|}{ Área ou região } & \multicolumn{1}{|c|}{$\begin{array}{c}\text { Ecossistema ou tipo de } \\
\text { vegetação }\end{array}$} & $\begin{array}{c}\text { Categoria de } \\
\text { UC }\end{array}$ \\
\hline 01 & Pureza & Savana (Cerrado) & $\mathrm{PI}$ \\
\hline 02 & Chapada do Apodi & Savana-estépica florestada & $\mathrm{PI}$ \\
\hline 03 & $\begin{array}{l}\text { Mata do Olho d'Água (Colégio } \\
\text { Agrícola de Judiai, Macaíba) }\end{array}$ & Floresta estacional decidual & $\mathrm{PI}$ \\
\hline 04 & $\begin{array}{l}\text { Serra de São José, Sitio Boqueirão } \\
\text { (Luis Gomes, São Miguel) }\end{array}$ & Savana-estépica florestada & $\mathrm{PI}$ \\
\hline
\end{tabular}




\begin{tabular}{|c|c|c|c|}
\hline 05 & Serra Bico da Arara (Acari) & $\begin{array}{l}\text { Savana-estépica arborizada, } \\
\text { andorinhões }\end{array}$ & $\mathrm{PI}$ \\
\hline 06 & Chapada do Apodi & Cavernas cársticas & US \\
\hline 07 & Inselbergs da Caatinga & Fauna e flora da Caatinga & PI e US \\
\hline 08 & Serras de Martins e Portalegre & Floresta estacional & PI e US \\
\hline 09 & $\begin{array}{l}\text { Serra dos Fundões (Carnaúba dos } \\
\text { Dantas) }\end{array}$ & $\begin{array}{l}\text { Savana-estépica arborizada e } \\
\text { pinturas rupestres }\end{array}$ & US \\
\hline 10 & $\begin{array}{l}\text { Serras do Boqueirão e do Samanau } \\
\text { (Agreste) }\end{array}$ & Savana-estépica arborizada & $\mathrm{PI}$ \\
\hline 11 & Pirangi-Búzios (Nísia Floresta) & Praias e Restinga arbustiva & PI e US \\
\hline 12 & São Tomé & Savana-estépica arborizada & $\mathrm{PI}$ \\
\hline 13 & $\begin{array}{l}\text { Serra da Bandeira (Caiçara do Rio } \\
\text { dos Ventos e Riachuelo) }\end{array}$ & Savana-estépica arborizada & $\mathrm{PI}$ \\
\hline 14 & João Câmara & $\begin{array}{l}\text { Savana-estépica arborizada e } \\
\text { Cerrado }\end{array}$ & $\mathrm{PI}$ \\
\hline 15 & Tangará (Agreste) & Savana-estépica arborizada & $\mathrm{PI}$ \\
\hline 16 & Tabuleiros de Caiçara do Norte & Praias e peixe-boi-marinho & US \\
\hline 17 & $\begin{array}{l}\text { Vista Serrana (ampliação da ESEC do } \\
\text { Seridó) }\end{array}$ & Savana-estépica arborizada & $\mathrm{PI}$ \\
\hline 18 & Serra do Chapéu (Currais Novos) & Savana-estépica arborizada & $\mathrm{PI}$ \\
\hline 19 & Lajedo Soledade (Apodi) & $\begin{array}{l}\text { Formações geológicas cársticas } \\
\text { e pinturas rupestres }\end{array}$ & US \\
\hline 20 & Ilha de Santa Luzia (Mossoró) & $\begin{array}{l}\text { Campos salinos e aves } \\
\text { migratórias }\end{array}$ & PI e US \\
\hline 21 & São Miguel do Gostoso & Praias e tartarugas marinhas & US \\
\hline 22 & $\begin{array}{l}\text { Plataforma interna do Rio Grande } \\
\text { do Norte }\end{array}$ & Peixe-boi-marinho, arrecifes & US \\
\hline 23 & Fazenda Bom Jardim & Mata Atlântica & PI e US \\
\hline 24 & $\begin{array}{l}\text { Serra do Feiticeiro (Lajes e Cerro } \\
\text { Corá) }\end{array}$ & Savana-estépica, beleza cênica & PI ou US \\
\hline 25 & Dunas do Norte & Restinga arbustiva e praias & PI e US \\
\hline
\end{tabular}

Quando se observa os dados das Unidades de Conservação Estadual eles apresentam uma defasagem entre o tempo de criação e a implantação com o zoneamento econômico-ecológico e o plano de manejo para cada uma das unidades criadas. No quadro geral as idades de criação das unidades não apresentam relação direta nem com a implantação de uma gestão efetiva, nem de estudos conclusivos de zoneamento e plano de manejo para legitimar a implantação das unidades de conservação. Entre as dificuldades encontradas está o ordenamento e conflito do uso e ocupação do solo nas unidades onde existem propriedades particulares de tamanhos diversos incluindo desde casas a propriedades rurais de médio e grande porte. Ou o problema da desapropriação muitas vezes com litígios e interesses opostos. Este fatos geram pressão sociais muitas vezes intransponíveis onde as leis federais de conservação não são consideradas como normas de conservacionistas da união mas sim porque a propriedade está em uma unidade de conservação. Um exemplo são as construções a beira-mar onde as populações tradicionais não entendem que a lei que proíbe as construções não são específicas da unidade de conservação 
mas sim do Patrimônio da União. Este e outros fatos levam muitas vezes a parte da população tradicional a ficar contra as unidades de conservação. Muitas comunidades tradicionais não compreendem que as unidades de conservação criadas são muito mais para assegurar sua fixação no seu local de origem do que uma defesa do patrimônio ambiental natural. Isto porque ambientes como mangue, dunas, lençóis de água entre outros já apresentam leis federais, como o código florestal, que os protegem inclusive com proteção permanente.

Um ponto que se observa é a dificuldade em se estudar e definir o zoneamento econômico-ecológico e o Plano de Manejo devido as diversas opiniões entre moradores e grupo de estudo formando impasses que muitas vezes que se prolongam por anos a fio. Seja por resultados pouco consistentes dos estudos realizados seja pelas necessidades dos moradores e a falta de uma estrutura sócio-econômica que banque a conservação da natureza que eles exploram. Os hábitos e costumes dos moradores devem está muito claros na gestão da unidade de conservação porque seus hábitos não são levados em conta pelos estudiosos, muitas intervencionistas focando em pontos conservacionistas que não levam em conta os usos e costumes do lugar. Se na unidade de conservação os "nãos" é regra, os próprios moradores ficaram contra a unidade. Dessa forma é essencial a compreensão da meta da conservação do meio ambiente incluindo a população residente como parte integrante dele. Abaixo está o quadro geral com os principais dados de criação, estágio de gestão e implantação das reservas estaduais do Rio Grande do Norte. Estas dificuldades discutidas são vividas por todos os técnicos que se colocam em interface com as comunidades das Unidades de conservação. O próprio autor deste trabalho sentiu estas dificuldades citadas nos trabalhos avaliados pelo método RAPPAM.

Quadro 1. Geral das unidades de conservação estadual do Rio Grande do Norte.

\begin{tabular}{|l|l|l|l|}
\hline UC Estaduais & $\begin{array}{l}\text { Local e Data de } \\
\text { Criação }\end{array}$ & $\begin{array}{l}\text { Estágio de } \\
\text { gestâo }\end{array}$ & Situação Atual \\
\hline $\begin{array}{l}\text { 1.Parque Estadual das Dunas } \\
\text { de Natal Jornalista Luiz Maria } \\
\text { Alves }\end{array}$ & $\begin{array}{l}\text { Natal, Área:1172ha, } \\
22.11 .1977 \\
35 \text { anos }\end{array}$ & $\begin{array}{l}\text { Gestão } \\
\text { Técnica } \\
\text { Coordenação } \\
\text { direta do } \\
\text { IDEMA }\end{array}$ & $\begin{array}{l}\text { Completamente } \\
\text { implantado com } \\
\text { plano de } \\
\text { manejo e } \\
\text { zoneamento } \\
\text { definidos }\end{array}$ \\
\hline $\begin{array}{l}\text { 2.Parque Estadual Florêncio } \\
\text { Luciano }\end{array}$ & $\begin{array}{l}\text { Parelhas. Área do } \\
\text { Açude do Boqueirão. } \\
\text { Área: 446,02ha. } \\
10.08 .1988 \\
24\end{array}$ & $\begin{array}{l}\text { Ausência de } \\
\text { instrumento } \\
\text { de gestão }\end{array}$ & $\begin{array}{l}\text { Área de } \\
\text { proteção em } \\
\text { processo de } \\
\text { revisão }\end{array}$ \\
\hline 3.Parque Ecológico do Cabugí & $\begin{array}{l}\text { Angicos. Área: 20162 } \\
\text { ha. 16.03.2000 } \\
12 \text { anos }\end{array}$ & $\begin{array}{l}\text { Ausência de } \\
\text { instrumento } \\
\text { de gestão }\end{array}$ & $\begin{array}{l}\text { Área de } \\
\text { proteção em } \\
\text { processo de } \\
\text { recategorização }\end{array}$ \\
\hline $\begin{array}{l}\text { 4.Área de Proteção Ambiental } \\
\text { de Piquiri- Uma }\end{array}$ & $\begin{array}{l}\text { Pedro Velho, } \\
\text { Canguaretama, } \\
\text { Várzea, Espírito Santo } \\
\text { e Goianinha. } \\
\text { 06.06.1990 e } \\
\text { ampliada em }\end{array}$ & $\begin{array}{l}\text { Conselho } \\
\text { Gestor em } \\
\text { consolidação. }\end{array}$ & $\begin{array}{l}\text { Plano de } \\
\text { Manejo em } \\
\text { discussão, sem } \\
\text { Zoneamento e } \\
\text { sede. }\end{array}$ \\
\hline
\end{tabular}




\begin{tabular}{|c|c|c|c|}
\hline & $\begin{array}{l}22.03 .2011 \\
22 \text { anos }\end{array}$ & & \\
\hline $\begin{array}{l}\text { 5.Área de Proteção Ambiental } \\
\text { de Genipabú }\end{array}$ & $\begin{array}{l}\text { Natal e Extremoz } \\
17.05 .1995 \\
17 \text { anos }\end{array}$ & $\begin{array}{l}\text { Conselho } \\
\text { Gestor } \\
\text { atuante }\end{array}$ & $\begin{array}{l}\text { Zoneamento e } \\
\text { Plano de } \\
\text { manejo } \\
\text { concluído. Área } \\
\text { implantada com } \\
\text { sede }\end{array}$ \\
\hline $\begin{array}{l}\text { 6.Área de Proteção Ambiental } \\
\text { de Bonfim-Guaraíra }\end{array}$ & $\begin{array}{l}\text { Nísia Floresta, S. José } \\
\text { de Mipibú, Arês, } \\
\text { Senador Georgino } \\
\text { Avelino, Goianinha e } \\
\text { Tibau do Sul. Área: } \\
42000 \text { ha 22.03.1999. } \\
13 \text { anos }\end{array}$ & $\begin{array}{l}\text { Ausência de } \\
\text { instrumento } \\
\text { de gestão }\end{array}$ & $\begin{array}{l}\text { Tem sede e } \\
\text { ausência de } \\
\text { Zoneamento e } \\
\text { Plano de } \\
\text { manejo. }\end{array}$ \\
\hline $\begin{array}{l}\text { 7.Área de Proteção Ambiental } \\
\text { dos Recifes de Corais }\end{array}$ & $\begin{array}{l}\text { Touro, Rio do Fogo e } \\
\text { Maxaranguape. } \\
\text { 06.06.2001. } \\
11 \text { anos }\end{array}$ & $\begin{array}{l}\text { Conselho } \\
\text { Gestor } \\
\text { atuantes }\end{array}$ & $\begin{array}{l}\text { Zoneamento e } \\
\text { Plano de } \\
\text { manejo } \\
\text { concluído. Área } \\
\text { implantada com } \\
\text { sede }\end{array}$ \\
\hline $\begin{array}{l}\text { 8. Reserva de Desenvolvimento } \\
\text { Sustentável Estadual Ponta do } \\
\text { Tubarão }\end{array}$ & $\begin{array}{l}\text { Macau e Guamaré. } \\
18.07 .2003 \\
9 \text { anos }\end{array}$ & $\begin{array}{l}\text { Conselho } \\
\text { Gestor } \\
\text { atuante }\end{array}$ & $\begin{array}{l}\text { Zoneamento e } \\
\text { Plano de } \\
\text { manejo a } \\
\text { concluir. Área a } \\
\text { ser implantada. } \\
\text { Tem sede. }\end{array}$ \\
\hline $\begin{array}{l}\text { 9.Parque Estadual Mata da } \\
\text { Pipa }\end{array}$ & $\begin{array}{l}\text { Tibau do Sul } \\
12.09 .2006 \\
6 \text { anos }\end{array}$ & $\begin{array}{l}\text { Conselho } \\
\text { Gestor com } \\
\text { funcionamen } \\
\text { to precário }\end{array}$ & $\begin{array}{l}\text { Zoneamento e } \\
\text { Plano de } \\
\text { manejo a } \\
\text { concluir }\end{array}$ \\
\hline
\end{tabular}

Além destas UCs criadas existe no IDEMA em processos diversos de criação 4 unidades de conservação: Apa Dunas do Rosado, em Porto do Mangue: Apa das Carnaúbas, em Açu; Parque dos Mangues, em Natal e Parque do Jiquí, em Natal e Parnamirim. Todos os estudos técnicos estão elaborados e hoje está em tramitação nos diversos órgãos do governo para a aprovação final de suas criações. Outro fato são estudos realizados pelo IDEMA já citados anteriormente que aponta para a necessidade de criação de novas Unidades de conservação em áreas de relevante interesse ambiental como: as caatingas, patrimônio arqueológico e espeleológico, brejos de altitude entre outros cuja tabela de prioridade ambiental está descrita quando citou-se o Relatório das áreas potenciais para Unidades de conservação. Nesta atual visão a prioridade não é mais criada por compensações de obras construídas, mas pelo valor ambiental das áreas. 


\section{CONCLUSÕES}

Em linhas gerais pode-se afirmar que houve mudanças no processo e objetivo das criações das unidades de conservação pelo estado do Rio Grande do Norte, mas ainda apresenta dificuldades na sua gestão com problemas que passa pela área técnica, social, econômica e política. A técnica pela falta de profissionais que consigam de forma transdisciplinar sistematizar o zoneamento econômico-ecológico e o Plano de Manejo com apoio da população local. Social pela elevada dificuldade de manter vivo o interesse das comunidades pelas unidades de conservação. Econômico pelos gastos em todo o processo e em projetos sócio-econômico-culturais que envolvam a população residente. Por último a vontade política de manter políticas públicas direcionadas para a conservação e proteção do meio natural e suas populações tradicionais ou que vivam em áreas de interesse ambiental seja como patrimônio ecológico como caatingas muito secas ou mananciais de água, mangues ou mesmo animais e plantas em extinção. A ausência do interesse político aumenta a morosidade na criação das unidades de conservação e principalmente na gestão que culmina em unidades de conservação implantadas.

\section{REFERENCIAS BIBLIOGRÁFICAS}

BRASIL. MINISTÉRIO DO MEIO AMBIENTE. Agenda 21 Brasileira: Resultado da Consulta Nacional. Brasília: MMA/PNUD, 2002.

. Agenda 21 Brasileira: Ações Prioritárias. Brasília: MMA/PNUD, 2002.

QUEIROZ, Fábio Albergaria. Meio ambiente e comércio internacional: relação sustentável ou opostos inconciliáveis? 2003. Dissertação (Mestrado em Desenvolvimento Sustentável).

BRASIL, Centro de Desenvolvimento Sustentável (CDS), Universidade de Brasília, Brasília. BRASIL, 1988. Constituição da República Federativa do Brasil, Senado Federal, Centro Gráfico, Brasília, 1988, 292 p.

BRASIL, 2000. Sistema Nacional de Unidades de Conservação da Natureza - SNUC: Lei no 9.985, de 18 de julho de2000. Brasília: MMA/SBF, 2000. p.32. Ementa.

ERVIN, J. Metodologia do WWF para avaliação rápida e a priorização do manejo de unidades de conservação (Rappam). São Paulo, SP, WWF-Brasil. 2003(a). 70 p. (Tradução WWF-Brasil).

IBAMA. Ecossistemas Brasileiros. Moacyr Bueno Arruda (org.). Brasília: Edições IBAMA, 2001.49 p.

IDEMA. Estudos técnicos e caracterização preliminar das áreas potenciais para criação de novas unidades de conservação no estado do Rio Grande do Norte. Edições do IDEMA, 2011.

LIMA, L. E. C., 1989. Considerações Ecológicas sobre O Vale do Paraíba do Sul, Centro Educacional Objetivo, São Paulo e Fundação Nacional do Tropeirismo, Caçapava, 46 p.

MILLER, K. R. Evolução do Conceito de Áreas de Proteção - Oportunidade para o Século XXI. In: Congresso Brasileiro de Unidades de Conservação, Curitiba, 1997.

SOAVINSKI. R. J. Sistema Nacional de Unidades de Conservação: Legislação e Política. In: XXX Congresso Brasileiro de Unidades de Conservação, Curitiba, 1997. 